\title{
Building damage assessment and settlement monitoring in subsidence-affected urban areas: case study in the Netherlands
}

\author{
Gianfranco Nicodemo, Dario Peduto, and Settimio Ferlisi \\ Department of Civil Engineering, University of Salerno, Via Giovanni Paolo II, 132-84084 Fisciano (SA), Italy \\ Correspondence: Gianfranco Nicodemo (gnicodemo@unisa.it)
}

Published: 22 April 2020

\begin{abstract}
Buildings in subsiding areas may suffer from settlements causing damages of different severity levels with high impact in terms of yearly economic losses. In these contexts, a systematic damage assessment jointly with continuous monitoring of relevant parameters (e.g. settlements exhibited by points located on the roof) can be extremely useful to control the building behaviour and develop forecasting models. In this regard, the paper presents the results of an integrated analysis carried out on a subsidence-affected urban area in the Netherlands where the availability of multi-temporal building damage surveys and a long DInSAR monitoring dataset allowed both retrieving quantitative empirical relationships between the cause (magnitude of the selected intensity parameter, IP) and the effect (recorded damage severity level, DL) and generating empirical fragility and vulnerability curves. The results pointed out the importance of considering the exact dating of the onset of building damage and the corresponding magnitude of the considered IP in the generation of quantitative forecasting models.
\end{abstract}

\section{Introduction}

Damage analysis and settlement monitoring of buildings at subsidence risk is a topic of particular concern when the most suitable strategies for land-use planning and urban management have to be identified. However, addressing this topic usually involves complex technical aspects, which include a thorough knowledge of the mechanisms, the properties of involved soils, the building/foundation typology, and the availability of (high quality and quantity) data gathered from the monitoring of buildings undergoing settlements. For this reason, an integrated approach based on the joint use of monitoring data, such as those provided by the processing of spaceborne Synthetic Aperture Radar (SAR) images via Differential Interferometry techniques (DInSAR), and information on the damage severity level recorded by buildings (classified during in situ surveys) can be extremely useful to set up reliable forecasting models tailored for managing the risk to exposed buildings and to develop suitable mitigation strategies. In this regards, with reference to a densely urbanized area in the Netherlands, where masonry buildings have been suffer- ing from subsidence-induced damage, this paper shows how the combination of the DInSAR-derived building settlements with the recorded damages (in the form of cracks on building façades) is helpful to develop damage forecasting models. In particular, empirical relationships between differential settlement $\Delta$ (selected as intensity parameter, IP) and damage severity level (DL) as well as empirical fragility curves are retrieved for masonry buildings in the study area. Moreover, the availability of multi-temporal building damage surveys, jointly with SAR data associated with the settlement monitoring, allows discussing the key role played by the exact dating of the onset and evolution of damage along with the corresponding value of the selected IP in deriving quantitative forecasting models that can be successfully used within procedures aimed at managing the risk to which buildings in subsiding areas are exposed.

\section{Case study}

The analyzed case study is the municipality of Zaanstad located in the northern part of the Netherlands (Fig. 1a). As 


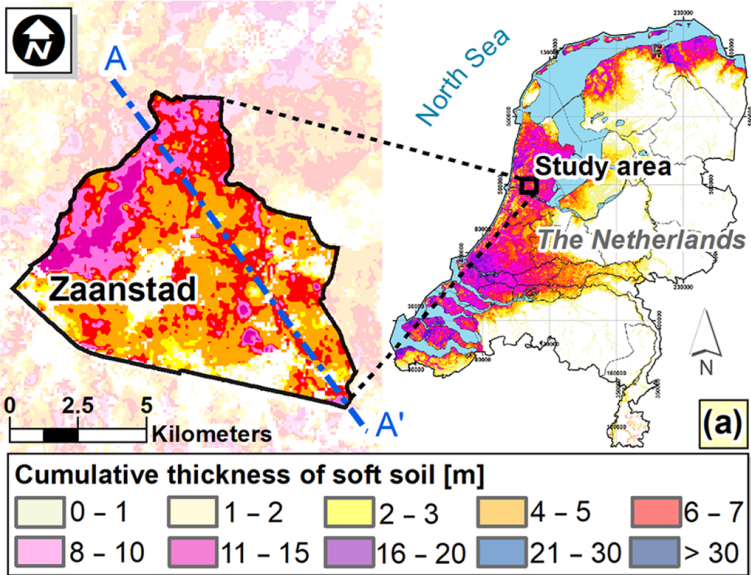

A Most probable lithological class (Section A-A') A'

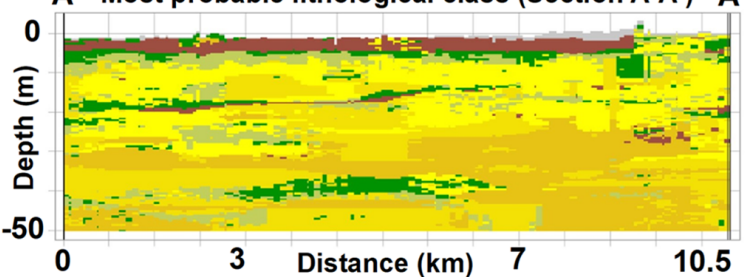

\begin{tabular}{|c|c|c|c|}
\hline \multicolumn{4}{|l|}{ Lithology } \\
\hline $\begin{array}{l}\text { Antrop } \\
\text { soil }\end{array}$ & Clay & Organic soil & $\begin{array}{l}\text { Clayey sand / } \\
\text { Sandy clay }\end{array}$ \\
\hline Gravel & $\begin{array}{l}\text { Sand, middle } \\
\text { category }\end{array}$ & $\begin{array}{l}\text { Sand, fine } \\
\text { category }\end{array}$ & $\begin{array}{l}\text { Sand, coarse } \\
\text { category }\end{array}$ \\
\hline
\end{tabular}

PREDISPOSING FACTORS

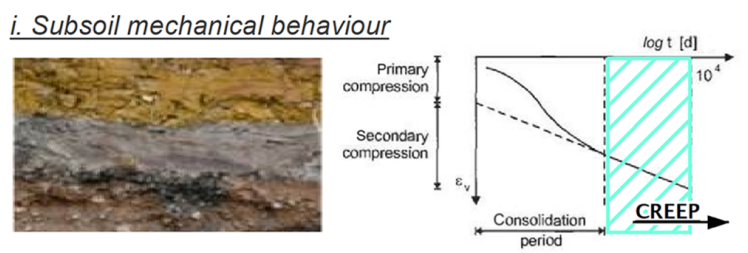

ii. Effects on foundations

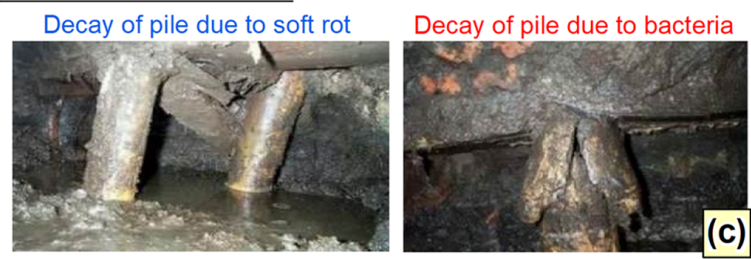

CONSEQUENCES
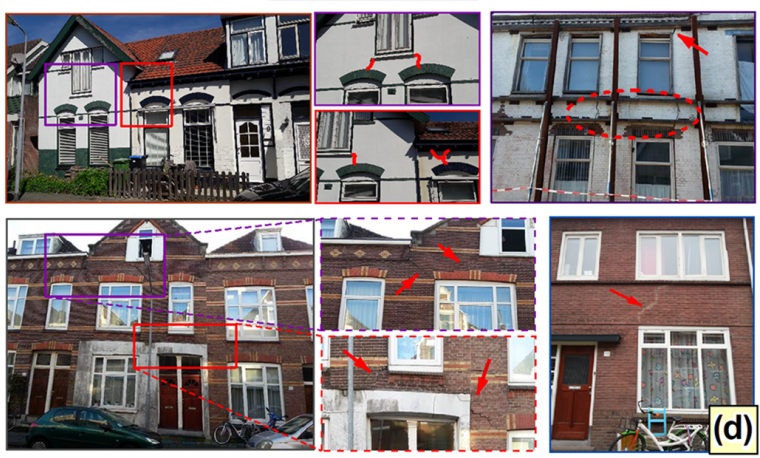

Figure 1. Zaanstad case study with (a) cumulative thickness of soft soils (organic and clayey) courtesy of Deltares; (b) geological crosssection (extracted from the portal of the Geological Survey of the Netherlands - DINOloket); (c) predisposing factors to settlements occurrence and (d) consequences in terms of damages to buildings.
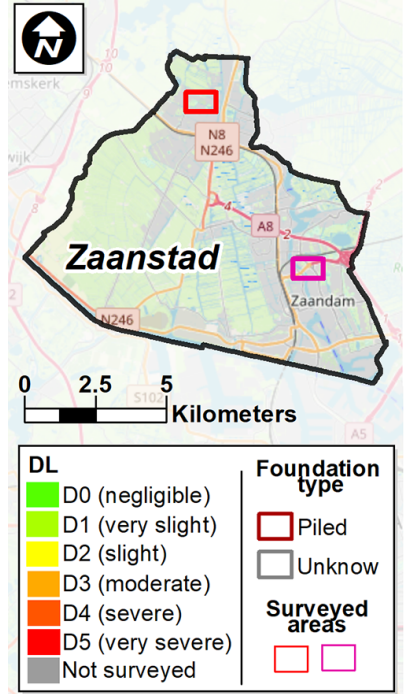
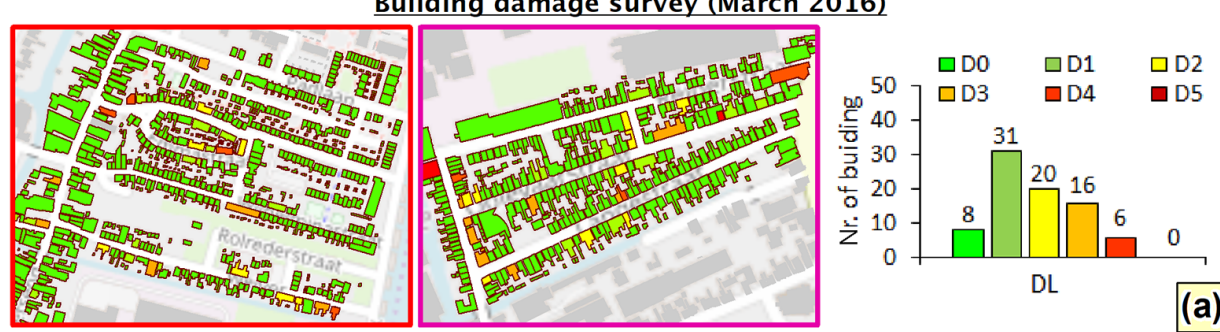

Building damage survey (April 2018)
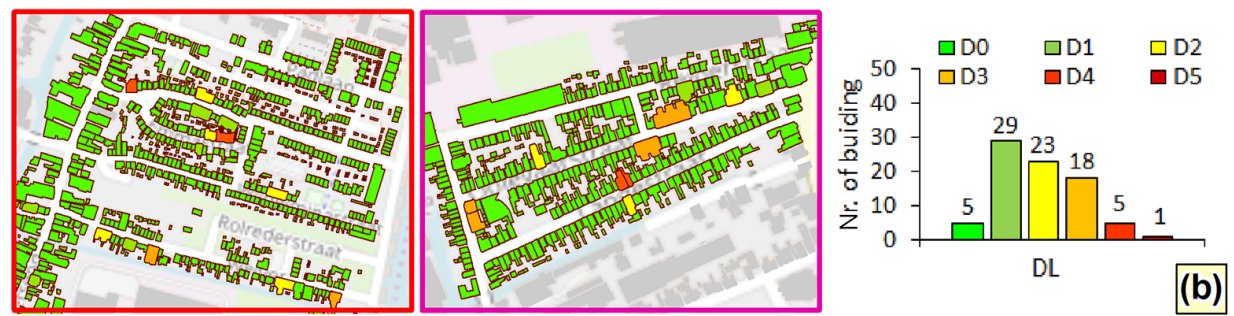

Figure 2. Maps of multi-temporal building damage surveys carried out in (a) March 2016 and (b) April 2018 and distributions of the recorded DL on 81 masonry buildings with pile foundation considered for the analysis. Source: Image from OpenStreetMap. 
a typical Dutch geological context, the subsoil of the area mainly consists of Holeocene clayey and peaty soil layers superimposed to sandy deposits of Pleistocene age (Stafleu et al., 2011). In detail, a generic cross-section along the A$\mathrm{A}^{\prime}$ profile (Fig. 1a, b) - extracted from the nationwide 3-D"GeoTop" model - shows that the upper deposit has a cumulative thickness not exceeding $10 \mathrm{~m}$, whereas the lower deposit includes some thin lenses of clay or sandy clay (Peduto et al., 2016, 2019). The presence of weak and compressible fine-grained (soft) soils in both deposits, characterized by high compressibility in both primary and secondary (or creeping) consolidation stages (Fig. 1c), represents one of the predisposing factors leading to the occurrence of settlements in the built-up area (Den Haan and Kruse, 2006; Peduto et al., 2017).

The above described mechanical behaviour of soft soil has promoted in the past the adoption on wooden piles in order to prevent large settlements of the masonry buildings. Nevertheless, in the last decades several piled foundations still in service posed urging problems due to the effects of wood decay (Klaassen and Creemers, 2012) associated with fungi or bacteria attack (Fig. 1c) that originate detrimental absolute/differential settlements. As a result, several buildings suffer from widespread damages (Fig. 1d) affecting the aesthetics or compromising either the functionality or even the stability. A multi-temporal building damage survey (Fig. 2), carried out in March 2016 and April 2018 by filling adhoc predisposed factsheets (Ferlisi et al., 2015; Nicodemo et al., 2017), is available for two selected neighbourhoods of the Zaanstad municipality. The DLs of surveyed masonry buildings with wooden pile foundations, assigned based on the analysis of crack patterns exhibited by building façades, were differentiated in six classes (from D0 $=$ negligible to D5 $=$ very severe) adapting those provided by Burland et al. (1977). The results of the two survey campaigns jointly with the distributions of the DLs recorded on 81 masonry buildings considered for the analysis are shown, respectively, in Fig. 2a and b. As for settlement monitoring, very highresolution DInSAR data provided by the processing via the Persistent Scatterer Interferometry (PSI) technique (Ferretti et al., 2001) of SAR images acquired by TSX radar sensor on the ascending orbit between February 2009 and April 2018 are available. The PSI velocities distribution over the two selected parts of Zaanstad are shown in Fig. 3.

\section{Cause-effect relationship analysis and results}

In order to set up reliable forecasting models tailored for managing the risk to the exposed buildings in subsidenceaffected urban areas, the relationship between the magnitude of the IP (cause) and recorded building DL (effect) was preliminarily retrieved. For this purpose, PSI data were used to derive the differential settlement $\Delta$ experienced by a given building. In particular, the vertical PSI-derived set-

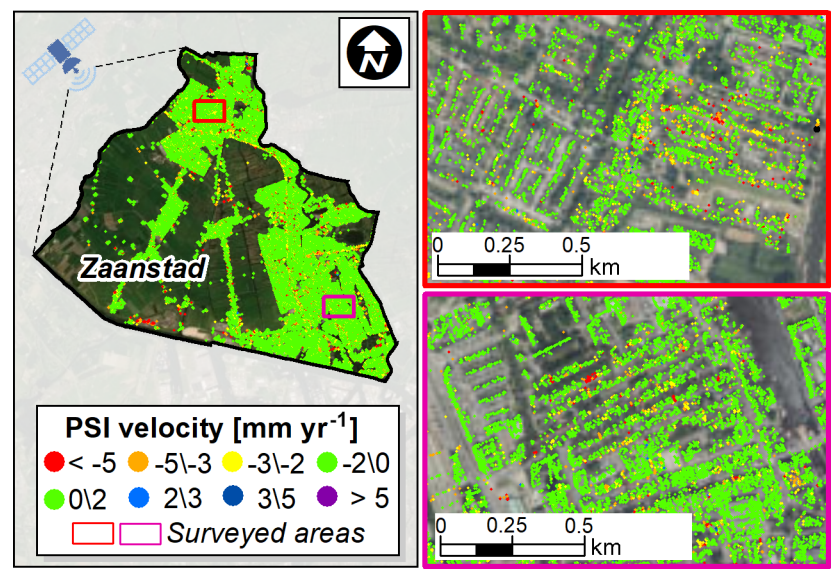

Figure 3. PSI velocity distribution on ascending orbit provided by the TSX radar sensor in the period 2009-2018. Source: Image from (C) Google Earth.

tlement measurements (i.e. computed by multiplying the average velocity recorded on the building roof for the observation period) were interpolated within the building's perimeter (Nicodemo et al., 2017; Peduto et al., 2019) and the $\Delta$ was assessed as the maximum difference of the recorded cumulative settlement profile along a longitudinal cross-section of the building (Nicodemo et al., 2020).

Merging the PSI-retrieved IP with the corresponding DL assigned to the buildings during the last in-situ damage survey (April 2018) allowed retrieving the empirical relationship (Fig. 4a) between $\Delta$ and DL. The obtained diagram (Fig. 4a) shows that the DL increases as the magnitude of selected IP $(\Delta)$, on average, increases.

Then, following the procedure described in Peduto et al. (2019), empirical fragility (Fig. 4b) and vulnerability (Fig. 4c) curves were generated.

The former were obtained by adopting as probabilistic model the log-normal distribution function, whose fragility parameters, median $\overline{\Delta_{i}}$ and standard deviation $\beta_{i}$, were computed using the maximum likelihood estimation method (Shinozuka et al., 2003):

$P\left(\right.$ Damage $\left.\geq D_{i} \mid \Delta\right)=\phi\left[\frac{1}{\beta_{i}} \ln \left(\frac{\Delta}{\overline{\Delta_{i}}}\right)\right]$

In particular, Eq. (1) provides the conditional probability $P(\cdot)$ for a randomly selected building at risk to be in, or exceed, a certain DL $\left(D_{i}\right)$ when the IP $(\Delta)$ equals a given value. The vulnerability curve, relating the expected mean level of damage severity $\left(\mu_{\mathrm{D}}\right)$ to a value of the IP $(\Delta)$ for a given building, was generated by fitting the empirical data obtained by multiplying the discrete probability $P_{i}$, associated with each $D_{i}$, for a numerical index $d_{i}$ (adapted from Pitilakis and Fotopoulou, 2015):

$\mu_{\mathrm{D}}(\Delta)=\sum_{i=0}^{D_{i}} P_{i} \cdot d_{i}$ 

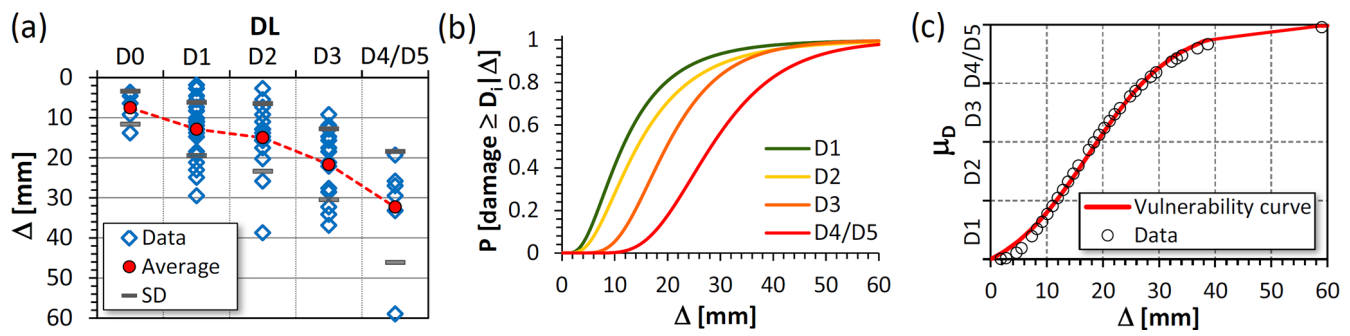

Figure 4. Empirical cause-effect relationships for masonry buildings in subsidence-affected urban area in terms of (a) damage severity level vs. differential settlements; (b) fragility curves and (c) vulnerability curve.

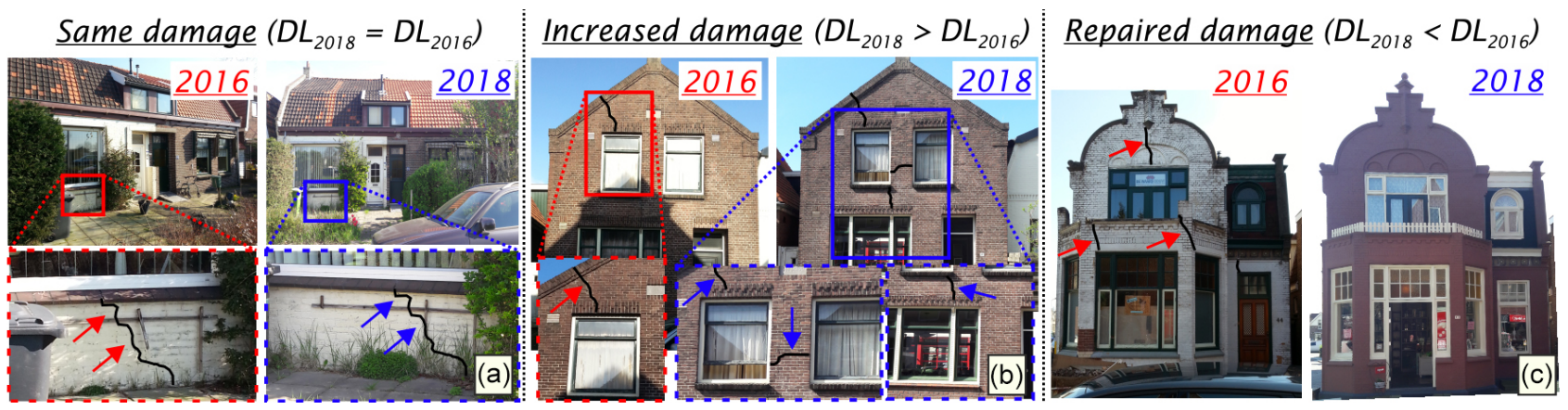

Figure 5. Comparison of building's DL recorded during March 2016 and April 2018 in-situ surveys: (a) same damage (DL2018 $\left.=\mathrm{DL}_{2016}\right)$; (b) increased damage $\left(\mathrm{DL}_{2018}>\mathrm{DL}_{2016}\right)$ and (c) repaired damage $\left(\mathrm{DL}_{2018}<\mathrm{DL}_{2016}\right)$.

using as regression model the tangent hyperbolic function (Lagomarsino and Giovinazzi, 2006):

$\mu_{\mathrm{D}}=a\left[b+\tanh \left(c \cdot \Delta_{i}+d\right)\right]$

with four fitting coefficients $(a, b, c$, and $d)$ determined for the analyzed building sample.

\section{Discussion and conclusions}

The combined use of monitoring PSI data and information on damages suffered by the structures allowed generating empirical cause-effect relationships and forecasting models as empirical fragility and vulnerability curves of masonry buildings undergoing settlements.

These empirical predictive tools, once further validated also with results of numerical analyses aimed at investigating the role played by both soil mechanical properties and the foundation deformation mode on the building response (Ferlisi et al., 2019), could provide a cognitive basis to investigate the vulnerability of buildings affected by settlements.

However, their exportability in urban areas presenting similar soils characteristics and urban fabric as well as their reliable use within procedures aimed at managing the risk require further studies concerning:

i. the exact dating of the onset of building damage (generally unknown) and/or its evolution in time;
Damage level (2018)

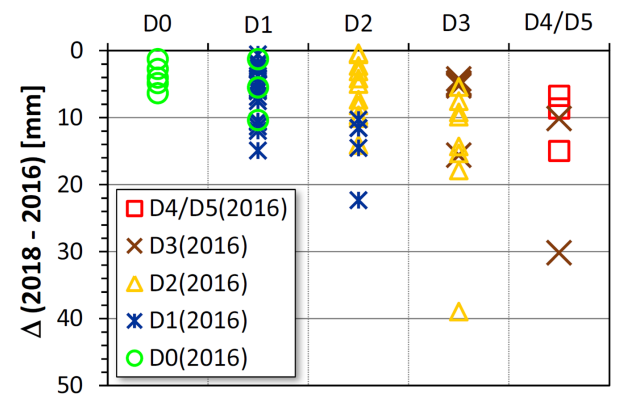

Figure 6. Building damage evolution (2016-2018) vs. increase of $\Delta$ in the same time interval.

ii. the real value of the selected IP that can be considered as direct cause of a certain DL.

From this point of view, the availability of a multitemporal damage survey jointly with a continuous monitoring of the selected IP (e.g., computed via PSI data) can help to overcome the above mentioned open issues. For this purpose, a preliminary analysis on the sample of 81 masonry buildings in Zaanstad area was carried out by comparing the DLs recorded during March 2016 with those dated April 2018 (Fig. 5); the cumulative values of $\Delta$ suffered by the buildings in the time interval spanning between the two surveys (2018-2016) were also computed. These latter were correlated with the evolution of the DLs recorded on the in- 
vestigated buildings sample in April 2018 (Fig. 6) with respect to their starting damage state in March 2016 (assumed as initial condition) and excluding those buildings which undergone a repair intervention (Fig. 5c).

The new retrieved $\Delta$ vs. DL relationship (Fig. 6) highlights that, in the time interval (2016-2018), most of the investigated buildings (53 out of a total of 72) exhibit the same DL as the one recorded in March 2016 (e.g., Fig. 5a), probably due to $\Delta$ values that turned out to be too low to induce a transition to higher DLs. Out of the remaining 19 buildings, some show an increase of DL (not greater than one level) that is associated to a substantial increase of $\Delta$ (e.g., DL that compromises their functionality (D3) or even their stability (D4/D5)); some others experienced a slight increase of $\Delta$, which, however, has induced a progression of the precedent damage state corresponding to a higher DL.

The sample of buildings exhibiting no damage in 2016, once further enriched with similar cases, could represent a sample of masonry buildings useful to investigate the "real" response (in terms of the onset and development of damages) of settlement-affected buildings in time. This could allow finding the tolerable/intolerable values of the selected IP (e.g., the differential settlement, $\Delta$ ) to be used within quantitative forecasting models for risk management of subsidenceaffected urban areas.

Data availability. The data supporting the results of this study are available within the paper. The building damage dataset could be available upon request for joint research purposes; whereas the ownership of the raw data relating to the TSX radar images used in this work belongs to SkyGeo Netherlands B.V. company.

Author contributions. All authors equally contributed to the work by conceiving the idea, designing the methodology, performing the analyses that allowed to retrieve the presented results, writing and revising the paper.

Competing interests. The authors declare that they have no conflict of interest.

Special issue statement. This article is part of the special issue "TISOLS: the Tenth International Symposium On Land Subsidence - living with subsidence". It is a result of the Tenth International Symposium on Land Subsidence, Delft, the Netherlands, 17-21 May 2021.

Acknowledgements. The authors gratefully acknowledge SkyGeo Netherlands B.V. for supplying PSI data and Roberto D'Angelo and Marco Morra (University of Salerno) who contributed to the research during their MSc theses activities carried out within the
ERASMUS + for Traineeship Agreement between University of Salerno (Italy) and SkyGeo Netherlands B.V.

\section{References}

Burland, J. B., Broms, B. B., and De Mello, V. F. B.: Behaviour of foundations and structures, Proc. of 9th Int. Conf. of SMFE, Japan, 1977, Japanese Society of Soil Mechanics and Foundation Engineering, Vol. 2, Tokyo, 495-546, 1977.

Den Haan, E. J. and Kruse, G. A. M.: Characterisation and engineering properties of Dutch peats, in: Character, edited by: Tan, T. S., Phoon, K. K., Hight, D. W., and Leroueil, S., Eng. Prop. Nat. Soils, Taylor \& Francis Group, London, 3, 2101-2133, 2006.

Ferlisi, S., Peduto, D., Gullà, G., Nicodemo, G., Borrelli, L., and Fornaro, G.: The use of DInSAR data for the analysis of building damage induced by slow-moving landslides, in: Engineering geology for society and territory, edited by: Lollino, G., Giordan, D., Crosta, G. B., Corominas, J., Azzam, R., Wasowski, J., and Sciarra, N., Springer International Publishing, Switzerland, Vol. 2, 1835-1839, 2015.

Ferlisi, S., Nicodemo, G., Peduto, D., Negulescu, C., and Grandjean, G.: Deterministic and probabilistic analyses of the 3D response of masonry buildings to imposed settlement troughs, GeoRisk, https://doi.org/10.1080/17499518.2019.1658880, online first, 2019.

Ferretti, A., Prati, C., and Rocca, F.: Permanent scatterers in SAR interferometry, IEEE T. Geosci. Remote Sens., 39, 8-20, 2001.

Klaassen, R. K. W. M. and Creemers, J. G. M.: Wooden foundation piles and its underestimated relevance for cultural heritage, J. Cult. Herit., 13, 123-128, 2012.

Lagomarsino, S. and Giovinazzi, S.: Macroseismic and mechanical models for the vulnerability and damage assessment of current buildings, B. Earthq. Eng., 4, 415-443, 2006.

Nicodemo, G., Peduto, D., Ferlisi, S., and Maccabiani, J.: Investigating building settlements via very high resolution SAR sensors, in: Life-Cycle of Engineering Systems, edited by: Bakker, J., Frangopol, D. M., and van Breugel, K., Taylor \& Francis Group, London, 2256-2263, 2017.

Nicodemo, G., Peduto, D., and Ferlisi, S.: Multi-parameter probabilistic vulnerability analysis of settlement-affected masonry buildings with shallow/piled foundations in soft soils: case studies in The Netherlands, Proc. of the VII CNRIG2019, Springer Nature Switzerland AG 2020, LNCE 40, 42-51, https://doi.org/10.1007/978-3-030-21359-6_5, 2020.

Peduto, D., Nicodemo, G., Maccabiani, J., Ferlisi, S., D’Angelo, R., and Marchese, A.: Investigating the behaviour of buildings with different foundation types on soft soils: two case studies in The Netherlands, Proc. of VI CNRIG2016, Procedia Engineer, 158, 529-534, https://doi.org/10.1016/j.proeng.2016.08.484, 2016.

Peduto, D., Nicodemo, G., Maccabiani, J., and Ferlisi, S.: Multi-scale analysis of settlement induced building damage using damage surveys and DInSAR data: a case study in The Netherlands, Eng. Geol., 218, 117-133, https://doi.org/10.1016/j.enggeo.2016.12.018, 2017.

Peduto, D., Korff, M., Nicodemo, G., Marchese, A., and Ferlisi, S.: Empirical fragility curves for settlement-affected buildings: analysis of different intensity parameters for seven hundred masonry buildings in The Netherlands, Soils Found., 59, 380-397, https://doi.org/10.1016/j.sandf.2018.12.009, 2019. 
Pitilakis, K. D. and Fotopoulou, S. D.: Vulnerability assessment of buildings exposed to co-seismic permanent slope displacements, Proc. of the XVI ECSMGE in Geotechnical Engineering for Infrastructure and Development, edited by: Winter, M. G., Smith, D. M., Eldred, P. J. L., and Toll, D. G., ICE Publishing, 151-153, 2015.

Shinozuka, M., Feng, M. Q., Kim, H. K., Uzawa, T., and Ueda, T.: Statistical Analysis of Fragility Curves, Technical report MCEER-03-0002, State University of New York, Buffalo, 2003.
Stafleu, J., Maljers, D., Gunnink, J. L., Menkovic, A., and Busschers, F. S.: 3D modeling of the shallow subsurface of Zeeland, the Netherlands, Netherlands J. Geosci.-Geol. En Mijnbouw, 90, 293-310, 2011. 